\title{
Characterization of the Microbes Isolated from Salacia reticulata Raw Material and its Extract: A Simple Method to Reduce the Microbial Load in Herbal Products
}

\section{Rajkumar Bhosale ${ }^{1}$, Sasidharan Sakkan ${ }^{2}$, Sanman Kolhe', Sadanand Yewale $^{1}$, Shivaswamy Matadha Rudraiah ${ }^{3}$ and Sriram Padmanabhan ${ }^{4 *}$}

${ }^{1}$ Herbal Division, Sava Healthcare Limited, Research Center, Chinchwad, Pune, India

${ }^{2} Q C$ Division, Sava Healthcare Limited, KIADB Industrial Area, India

${ }^{3}$ Production Team, Sava Healthcare Limited, KIADB Industrial Area, India

${ }^{4}$ Head, R\&D, SAVA Healthcare Limited, Research Center, MIDC, Chinchwad, Pune, India

*Corresponding Author: Sriram Padmanabhan, Head, R\&D, SAVA Healthcare

Limited, Research Center, MIDC, Chinchwad, Pune, India.
Received: October 04, 2021

Published: November 30, 2021

(C) All rights are reserved by Sriram

Padmanabhan., et al.

\section{Abstract}

The study investigated and characterized the microbes that contaminate Salacia reticulata herbal extracts used as an antidiabetic herbal formula. Also investigated was the microbial load of these herbal powders by pour plate technique and HiChrome agar spread plate methods. The characterization of the isolated microbes confirmed the dominance of members of the genus Bacillus by 16 sRNA sequencing. The fungal sps was found to be Aspergillus that was present in the raw material and also in the dry powder extract of Salacia. While the bacterial count was in the range of $10^{4}$ to $10^{5} \mathrm{cfu} / \mathrm{g}$, the fungal count of Salacia extract ranged from $2.0 \times 10^{1} \mathrm{cfu} / \mathrm{g}$ to $1.9 \times 10^{2} \mathrm{cfu} / \mathrm{g}$. The isolated bacteria showed sensitivity towards Tetracycline, Gentamycin, Tobramycin, Kanamycin, Streptomycin, Ampicillin, Doripenum, Tripethoprim, Rifampicin and Fusidic acid and resistance towards the action of Azithomycin, Penicillin G, Carbenecillin, Moxifloxacin, Vancomycin and Nalidixic acid. Since tetracycline is a heat-labile antibiotic, we carried out a downstream process of extraction of one of the herbal raw material of Salacia reticulata with water with and without tetracycline. The obtained Salacia extract powders were then subjected to microbial counts and the results indicate $>99.99 \%$ reduction in the bacterial and yeast and molds load by the proposed manufacturing process. Similar rate of microbial load reduction was seen when the Salacia extract with the microbial load of $>10^{4} \mathrm{cfu} / \mathrm{g}$ was treated with tetracycline. The residual tetracycline in the final extract preparations was lesser than $5 \%$ to the original concentration used. This study emphasizes the need for constant monitoring and control of the standards of herbal medicines and discloses a simple method to reduce the microbial load present in the herbal samples using antibiotics so that after treatment, the microbial load are well within WHO standard.

Keywords: Aspergillus; WHO; Microbes; Salacia reticulata

\section{Introduction}

Medicinal plants harbor potential endophytic microbes such as bacteria, yeast and fungi and benefit from their bioactive compounds. The microbiological background of such microbes, present in the roots, shoots and endosphere [1,2], depends on several environmental factors and exerts an important impact on the overall quality of herbal products and preparations.

According to a World Health Organization (WHO) survey, about 70 to $80 \%$ of the world's populations, particularly in the develop- 
ing countries, rely on non-conventional medicines, mainly from herbal sources, for their primary healthcare including elderly population $[3,4]$. With the advent of global expansion of the herbal medicines market, there is increase demand in herbal products and hence concerns around their composition and safety are being recognized. In traditional medicines, medicinal plants have been in use since years since they represent a very important source of bioactive molecules that display antibacterial, antiviral, and antifungal properties [5].

Like conventional medicines, there is a great deal of effort put by many manufacturers to ensure safety, quality, and efficacy of herbal medicines, while some lack standard practice to manufacture quality products due to lack of stringent regulatory requirements resulting in free selling of such products in the market with little or no restraint. The safety of traditional and herbal medicines has therefore become a major concern to both national health authorities and the general public [6,7].

Most of the herbal raw materials support some form of microbial growth, depending on its nutritive properties and moisture contents. Since there are no obvious signs of spoilage of such raw materials, it is advisable to have knowledge of the microbial contents of all the herbal drugs and medicines so that appropriate caution is practiced during manufacturing and packaging and there is constant quality assessment of herbal materials in the market in order to ensure that medicinal plant materials and products are suitable for human consumption [8]. Many of the medicinal plant materials carry a large number of microbes originating from the soil that may be introduced during harvesting, handling, and production of various herbal remedies [9-11]. Escherichia coli and Bacillus cereus are some of the bacteria identified in herbal medicinal powders and molds such as Penicillium species, Fusarium species, and Aspergillus species are reported [12].

In developing countries, herbal extracts are recognized as pharmaceutical medicine and are used as complementary medicine and since consumptions of such extracts are in high volumes, adequate supervision is required before these are released directly into the market $[13,14]$.

Salacia reticulata is known for the treatment of diabetes in ayurvedic medicine. The roots and stem of this plant is prone to microbial contamination and insect infestation during storage and transportation causing concerns in maintenance of quality and prevent economic loss $[15,16]$. This study evaluates the microbial load in Salacia root extract and characterizes pathogens by sequencing and examined its antibiotic susceptibility. The microbial diversity in the Salacia reticulata extract was examined by aerobic plate count method and microbial isolates were identified based on their morphological, cultural, biochemical characteristics and 16 sRNA sequencing. This is the first report on identification of microbes in the raw material and extract of Salacia reticulata roots and opens up a simple and cost-effective method to reduce the microbial load to acceptable limits for human consumption.

\section{Materials and Methods}

Chemicals and reagents

Biolog GEN III micro plates for aerobes (Cat. No. 1030, Biolog), and Inoculating Fluid B (Cat. No. 72402, Biolog) were purchased from Biolog, Hayward, CA 94545, USA.

Plant materials

Stem and roots of Salacia reticulata were collected from different regions of India. The identity of Salacia was confirmed at Durva Herbal Centre, Chennai, Tamilnadu, India. The freshly collected samples of stem and roots were stored at room temperature, protected from light and humidity before processing. Commercial samples of Salacia extract was collected from the production unit, Sava Healthcare, Malur, Karnataka.

\section{Preparation of Salacia root extracts}

$100 \mathrm{~g}$ of Salacia roots was extracted with 4 volume of DM water w.r.t batch size for three times (each $3 \mathrm{~h}$ ) at temperature $80^{\circ} \mathrm{C}$. After extraction, all three extraction fluids were pooled and concentrated on rotary evaporator at $55-60^{\circ} \mathrm{C}$ to obtain a dry powder of Salacia extract.

Isolation of the endophytic bacteria and fungus from Salacia reticulata roots

$10 \mathrm{~g}$ of Salacia reticulata extract was mixed with $100 \mathrm{~mL}$ sterile distilled water and dissolved completely. The solution was brought to boiling for $5 \mathrm{~min}$ and $1 \mathrm{~mL}$ of sample was taken in a sterile petri dish. 5-20 mL of dextrose peptone agar was poured into petri dish and incubated at $55^{\circ} \mathrm{C}$ for $36-48 \mathrm{~h}$. The isolated colony from DPA plate was selected and streaked on Soybean casein digest agar/Nutrient agar incubated at $55^{\circ} \mathrm{C}$ for additional $36-48 \mathrm{~h}$.

Citation: Sriram Padmanabhan., et al. "Characterization of the Microbes Isolated from Salacia reticulata Raw Material and its Extract: A Simple Method to Reduce the Microbial Load in Herbal Products". Acta Scientific Microbiology 4.12 (2021): 119-129. 
For isolation of the fungus, $10 \mathrm{~g}$ of the Salacia extract was taken and added to $90 \mathrm{~mL}$ of Sabouraud's Dextrose Broth and homogenized for $2 \mathrm{~min} .1 \mathrm{~mL}$ of such a homogenized sample was taken into sterile petri dish and $15-20 \mathrm{~mL}$ of Sabourad's dextrose agar was poured and plates incubated at $20-25^{\circ} \mathrm{C}$ for $3-5$ days. Selected isolated colony from SDA plate was streaked on Sabourad's dextrose agar at $25^{\circ} \mathrm{C}$ for $3-5$ days and stored appropriately for further analysis.

For isolation of bacteria at room temperature, one gram of Salacia reticulata root extract or Salacia reticulata raw material (powdered) was suspended in $9 \mathrm{~mL}$ of sterile saline solution and mixed by vortexing for 5-10 min. $50 \mu \mathrm{L}$ of powder suspension was transferred in sterile petriplate and $20-25 \mathrm{~mL}$ of sterile molten Hi-chrome universal differential agar medium was poured. Agar plates were allowed to solidify and the plates incubated at $37^{\circ} \mathrm{C}$ for $24 \mathrm{~h}$. After incubation, plates were observed for different colored colonies. Different types of colonies were selected and purified by sub culturing on Hi-chrome universal differential agar. The isolated cultures SBC1, SBC2, SBC3 and SBC4 were subjected to PCR sequencing as described before.

Identification of the bacterial strain by 16sRNA sequencing

Bacterial culture

The culture plates were sub-cultured on nutrient agar at $55^{\circ} \mathrm{C}$ for 24 hours. Upon sub-culturing based on morphology two different bacterial colonies were observed and each colony was subjected to $16 \mathrm{~S}$ rDNA sequencing individually.

\section{DNA extraction}

DNA was extracted from bacterial culture using the QIAmp DNA Minikit (Qiagen) as per manufacturer's instructions, with a final elution volume of $50 \mu \mathrm{L}$. Extracted DNA was stored at $4{ }^{\circ} \mathrm{C}$ until required for PCR.

\section{PCR amplification}

The $1 \mu \mathrm{L}$ of bacterial DNA extract and controls were amplified with $1 \mu \mathrm{L}$ of $10 \mu \mathrm{M}$ primers (16s FP: 5' AGAGTTTGATCCTGGCTCAG $3^{\prime}$ and reverse primer (TCTACGCATTTCACCGCTAC), $3.5 \mu \mathrm{L}$ of GoTaq Green Mastermix (Promega), $3.5 \mu \mathrm{L}$ of nuclease free water. Amplification conditions for the PCR assay was as follows: $5 \mathrm{~min}$ at $94^{\circ} \mathrm{C}$ to denature the DNA, followed by 30 cycles of denaturation at $94^{\circ} \mathrm{C}$ for $30 \mathrm{sec}$, primer annealing at $55^{\circ} \mathrm{C}$ for $10 \mathrm{sec}$ and strand extension at $72^{\circ} \mathrm{C}$ for $30 \mathrm{sec}$ on a Eppendorf thermalcycler. PCR products were separated on a $2 \%$ agarose gel and DNA bands were visualized with ethidium bromide.

Primers and excess nucleotides were removed from the amplified DNA using a PCR clean-up kit (Qiagen). The amount of DNA in the cleaned-up product was quantified by comparing the intensity of the band to bands of known intensity in a HyperLadder marker (Bioline). Spiked samples were included with each PCR to determine whether or not the sample was inhibited. Spiked samples contained $1 \mathrm{cfu} / \mathrm{ml}$ of $E$. coli culture.

\section{PCR sequencing and sequence analysis}

Purified PCR products were sequenced in the forward and reverse direction in separate reactions. Each reaction contained $1 \mu \mathrm{L}$ of template DNA, $1 \mu \mathrm{L}$ of the appropriate PCR primer $(0.5 \mu \mathrm{M}), 1 \mu \mathrm{L}$ of nuclease water and $2 \mu \mathrm{L}$ of Big Dye Terminator v3.1 Ready Reaction Mix (Applied Biosystems). Each reaction was heated to $96^{\circ} \mathrm{C}$ for $1 \mathrm{~min}$, followed by 35 cycles at $96^{\circ} \mathrm{C}$ for $10 \mathrm{sec}, 55^{\circ} \mathrm{C}$ for $5 \mathrm{sec}$ and $60^{\circ} \mathrm{C}$ for $1 \mathrm{~min}$. The sequencing products were purified using an ethanol precipitation method to remove unincorporated reagents and ensure a neutral charge. To the sequencing reaction $0.5 \mu \mathrm{L}$ of 0.5M EDTA was added and vortexed briefly for homogenization of the reaction mixture. The homogenized reaction mixture, was further washed by adding $21 \mu \mathrm{L}$ of ethanol precipitation mix $(1 \mu \mathrm{L}$ of $3 \mathrm{M}$ sodium acetate and $20 \mu \mathrm{L}$ of absolute ethanol) and centrifuging at $4000 \mathrm{rpm}$ for $15 \mathrm{~min}$. The washing step was repeated twice. The pelleted DNA was dried by incubating in concentrator for $5 \mathrm{~min}$ at room temperature under vacuum condition. The dried DNA pellet was reconstituted in $10 \mu \mathrm{L}$ of formamide and denatured by heating the samples at $95^{\circ} \mathrm{C}$ and then snap cooling over ice. The denatured samples were loaded onto a 3730xl Genetic Analyzer Capillary Array for detection (Applied Biosystems). One forward and one reverse sequences for each sample were aligned using BioEdit to obtain a composite sequence. The quality of each sequence trace was visually assessed and poor quality sequence was edited and removed. Organisms were identified for each assay by comparing consensus sequences to a database library of known 16S rRNA gene sequences in GenBank (http://www.ncbi.nlm.nih.gov/blast/ Blast.cgi) by multiple sequence alignment. The bacterial source of the sequence was identified by matching it with a sequence with the highest maximum identity score from the GenBank database. Where more than one bacterial species had the same highest score,

Citation: Sriram Padmanabhan., et al. "Characterization of the Microbes Isolated from Salacia reticulata Raw Material and its Extract: A Simple Method to Reduce the Microbial Load in Herbal Products". Acta Scientific Microbiology 4.12 (2021): 119-129. 
the species identification of the test organism was deduced based upon the taxonomy hits.

\section{Fungal genomic DNA isolation}

The DNA from the isolated fungus was isolated using Macherey Nagel Nucleospin kit, as per manufacturer's instructions. Fungal ITS region gene was amplified using standard PCR reaction using forward (ITS1: 5' TCCGTAGGTGAACCTGCGG 3') and reverse primers (ITS4: 5' TCCTCCGCTTATTGATATGC 3'). The primer pair ITS1 and ITS4 was used in a PCR reaction with an annealing temperature of $45^{\circ} \mathrm{C}$. The PCR conditions included an initial denaturation at $95^{\circ} \mathrm{C}$ for 5 minutes followed by 35 cycles of denaturation, annealing and extension at 95,45 and $72^{\circ} \mathrm{C}$ respectively for $30 \mathrm{sec}$ each. After a finale extension of $7 \mathrm{~min}$ at $72^{\circ} \mathrm{C}$, the PCR amplicon (600 bp) products was purified by using exosap it kit (Invitrogen) and were directly sequenced using an ABI PRISM BigDye Terminator V3.1 kit (Applied Biosystems, USA). The sequences were analyzed using Sequencing Analysis 5.2 software. BLAST analysis was performed at Blast N site at NCBI server (http://www.ncbi.nlm.nih.gov/BLAST). DNA sequencing was performed using one of the PCR primers.

Phenotypic characterization of Salacia bacterial isolate (SBC 0)

The Salacia bacterial culture was streaked on the soybean casein digest agar (SCDA) and incubated at $35^{\circ} \mathrm{C}$ for $24 \mathrm{~h}$. The protocol B was used for the phenotypic characterization of SBC 0. Isolated colonies of SBC 0 were suspended in inoculating fluid (IF B) to get inoculum of recommended cell density. $100 \mu \mathrm{L}$ of inoculum was added in each well of 96 Biolog GEN III microplates and incubated at $35{ }^{\circ} \mathrm{C}$ for $24 \mathrm{~h}$. After incubation, the plates were analyzed using MicroStation with Biolog's microbial identification software and phenotypic or metabolic fingerprint of SBC 0 was compared with Biolog database.

Antibiotic sensitivity of the isolated bacteria by agar diffusion assay

Pre-grown culture of bacterial isolate was used as inoculum for antibiotic susceptibility assay. The colonies of bacterial strain were suspended in sterile saline solution ( $5 \mathrm{~mL}$ ) to get inoculum for agar diffusion assay. The turbidity of the inoculum was adjusted to $0.5 \mathrm{McF}$ arland standard. The suspension spread on agar surface of SCDA plates. Antibiotic sensitivity discs were placed on the agar surface using sterile forceps. Agar plates were incubated at $35{ }^{\circ} \mathrm{C}$ for $18 \mathrm{~h}$. After incubation of $18 \mathrm{~h}$, plates were observed for zone of inhibition against bacterial strain and diameters of zone of inhibition were recorded.

\section{Salacia trials}

The powdered raw material of Salacia reticulate roots was processed with water extraction and the extraction fluids was treated with and without tetracycline at 50 and $100 \mu \mathrm{g} / \mathrm{mL}$ final concentration. After $16 \mathrm{~h}$, the treated and the untreated materials were treated with activated charcoal at $0.5 \%$ final concentration and the liquids were evaporated in a rotary evaporator. The extracts, thus prepared were tested for microbial load. Similar process was followed for Salacia extract treated with and without tetracycline.

Chromatographic conditions for HPLC analysis of tetracycline Buffer solution Preparation

Dissolved 0.14 gm of potassium dihydrogen phosphate $\left(\mathrm{KH}_{2} \mathrm{PO}_{4}\right)$ in $900 \mathrm{~mL}$ of water, adjusted pH 2.8 with $0.02 \%$ ortho-phosphoric acid, made the final volume up to $1000 \mathrm{~mL}$ with water, mixed, degased and filtered through $0.45 \mu$ filter before use.

\section{Chromatographic conditions}

The chromatographic separation, using HPLC, was performed with gradient elution of mobile phase $\mathrm{A}\left(\mathrm{KH}_{2} \mathrm{PO}_{4}\right.$ buffer $)$ and mobile phase $\mathrm{B}$ (pure acetonitrile). The gradient program was set as (time/\% B) 0/10, 10/20, 20/50, 25/90, 30/90, 33/10, 35/10 which pumped the phases at a rate of $1 \mathrm{~mL} / \mathrm{min}$. The column used was Inertsil ODS, 3V, $250 \times 4.6 \mathrm{~mm}$ and $5 \mu \mathrm{m}$, with the column temperature of $30^{\circ} \mathrm{C}$. The injection volume of the samples was kept at $20 \mu \mathrm{L}$ and the tetracycline peak was observed at $277 \mathrm{~nm}$. The run time was $35 \mathrm{~min}$ and the tetracycline peak was seen at $10 \mathrm{~min}$.

\section{Standard and sample preparation}

$10 \mathrm{mg}$ of Tetracycline hydrochloride (Hi-media) was weighed and dissolved in $10 \mathrm{~mL}$ of water. For sample preparation, $10 \mathrm{mg}$ of the herbal extract was taken in a $10 \mathrm{~mL}$ volumetric flask, re-suspended in $5 \mathrm{~mL}$ of water and sonicated to dissolve the antibiotic completely. After making up the volume to $10 \mathrm{~mL}$ with water, the solution was filtered through $0.45 \mu$ sterile filter and used for HPLC injections.

Citation: Sriram Padmanabhan., et al. "Characterization of the Microbes Isolated from Salacia reticulata Raw Material and its Extract: A Simple Method to Reduce the Microbial Load in Herbal Products". Acta Scientific Microbiology 4.12 (2021): 119-129. 
Characterization of the Microbes Isolated from Salacia reticulata Raw Material and its Extract: A Simple Method to Reduce the Microbial Load in Herbal Products

\section{Results}

Genomic identification of the isolated organisms

Based on sequence alignment analysis over NCBI BLAST server, the test isolate SBC0 was identified as Bacillus licheniformis with a sequence similarity of $>98.65 \%$ while SBC1, SBC2, SBC3 and SBC4 are Bacillus subtilis, Bacillus zanthoxyli, Bacillus subtilis and Bacillus aryabhattai, respectively (Supplementary Figures S1, S2, S3 and S4). The fungal colony isolated from Salacia extract was identified as Aspergillus sps. (Supplementary Figure S5).

\section{Biochemical characterization of Salacia bacteria SBC 0}

Only the Salacia bacteria isolated at $55^{\circ} \mathrm{C}$ was processed for generating a metabolic/phenotypic fingerprint with Biolog's database. The biochemical characterization of SBC 0 revealed that it was able to utilize substrates such as dextrin, D-maltose, D-trehalose, Dcellulobiose, gentibiose, sucrose, $\beta$-methyl-D-glucoside, D-salicin, $\mathrm{N}$-acetyl-D-glucosamine, $\mathrm{N}$-acetyl-D-mannosamine, D-glucose, D- mannose, Fructose, D-mannitol, myo-insitol, glycerol, pectin, D-galactouronic acid, gluconic acid, D-glucornic acid, L-lactic acid, citric acid and D-malic acid.

\section{Antibiotic sensitivity of the isolated organisms}

Table 1 gives the antibiotic sensitivity of the isolated bacteria from Salacia extract. It is evident from this table that the isolated organisms are sensitive to tetracycline, gentamycin, tobramycin, kanamycin, streptomycin, ampicillin, doripenum, tripethoprim, rifampicin and fusidic acid while it was resistant to the action of Azithomycin, Penicillin G, Carbenecillin, Moxifloxacin, Vancomycin, Nalidixic acid. The antibiotic sensitivity pattern of all the organisms was found to be different supporting the differences seen from genomic characterization studies. Figure 1 (panel a) shows the growth of SBC0, SBC1, SBC2, SBC3 and SBC4 bacteria isolated from Salacia raw material which on Hichrome agar plates which are identical to the bacteria isolated from the Salacia extract (Figure 1, panel b).

\begin{tabular}{|c|c|c|c|c|c|c|c|c|c|c|c|}
\hline \multirow{2}{*}{$\begin{array}{l}\text { SR } \\
\text { No. }\end{array}$} & \multirow[t]{2}{*}{ Antibiotic } & \multicolumn{2}{|c|}{ SBC 0 } & \multicolumn{2}{|r|}{ SBC 1} & \multicolumn{2}{|r|}{ SBC 2} & \multicolumn{2}{|r|}{ SBC 3} & \multicolumn{2}{|r|}{ SBC 4} \\
\hline & & $\begin{array}{c}\text { DZI } \\
(\mathrm{mm})\end{array}$ & $\begin{array}{c}\text { Antibiotic } \\
\text { Suscepti- } \\
\text { bility }\end{array}$ & $\begin{array}{c}\text { DZI } \\
(\mathrm{mm})\end{array}$ & $\begin{array}{c}\text { Antibiotic } \\
\text { Susceptibility }\end{array}$ & $\begin{array}{c}\text { DZI } \\
(\mathrm{mm})\end{array}$ & $\begin{array}{c}\text { Antibiotic } \\
\text { Susceptibility }\end{array}$ & $\begin{array}{c}\text { DZI } \\
(\mathrm{mm})\end{array}$ & $\begin{array}{c}\text { Antibiotic } \\
\text { Susceptibility }\end{array}$ & $\begin{array}{c}\text { DZI } \\
(\mathrm{mm})\end{array}$ & $\begin{array}{c}\text { Antibiotic } \\
\text { Susceptibil- } \\
\text { ity }\end{array}$ \\
\hline 1 & Tetracycline & 31 & Sensitive & 16 & Sensitive & 23 & Sensitive & 18 & Sensitive & 21 & Sensitive \\
\hline 2 & Azithromycin & - & Resistant & 15 & Intermediate & 19 & Sensitive & 17 & Sensitive & 19 & Sensitive \\
\hline 3 & Tobramycin & 23 & Sensitive & 15 & Intermediate & 17 & Sensitive & 16 & Sensitive & 18 & Sensitive \\
\hline 6 & Kanamycin & 22 & Sensitive & 21 & Sensitive & 18 & Sensitive & - & Resistant & 17 & Sensitive \\
\hline 7 & Ampicillin & 21 & Sensitive & 17 & Sensitive & 11 & Resistant & 11 & Resistant & - & Resistant \\
\hline 8 & Doripenam & 47 & Sensitive & 35 & Sensitive & 29 & Sensitive & 31 & Sensitive & 29 & Sensitive \\
\hline 9 & Penicillin -G & - & Resistant & - & Resistant & - & Resistant & 05 & Resistant & - & Resistant \\
\hline 10 & Carbenicillin & - & Resistant & 16 & Intermediate & 11 & Resistant & 20 & Sensitive & 14 & Resistant \\
\hline 15 & Rifampicin & 23 & Sensitive & 23 & Sensitive & 13 & Resistant & 18 & Sensitive & 11 & Resistant \\
\hline 16 & Fusidic acid & 19 & Sensitive & 18 & Sensitive & 16 & Sensitive & 12 & Resistant & 11 & Resistant \\
\hline
\end{tabular}

Table 1: Comparative study of antibiotic susceptibility of Salacia bacterial isolates.

DZI: Diameter of Zone of Inhibition.

\section{Salacia trials}

Figure 2A and 2B shows the flow chart of processing of Salacia raw material and the extract respectively. It is clear from Table 2A that reduction of the microbial load of Salacia is dependent on the concentration of the tetracycline used for inactivating the microbes while Table 2B shows the residual yeast and mold levels after these 


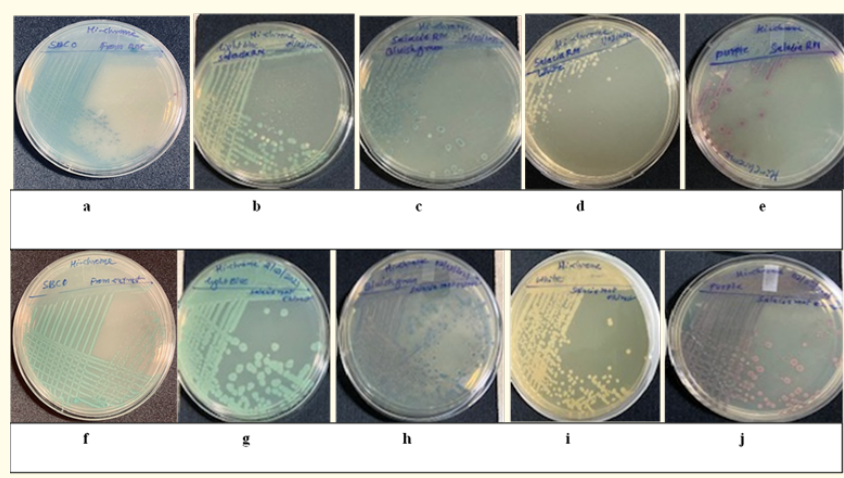

Figure 1: Growth of all bacterial isolates from Salacia reticulata raw material (panel A) and Salacia extract (panel B) on Hichrome Universal differential agar plates.

treatments. For achieving maximum killing of the inherent bacteria in Salacia, one needs tetracycline in the concentration of $100 \mu \mathrm{g} /$ $\mathrm{mL}$. Hence, for further experiments, tetracycline was used at 100 $\mu \mathrm{g} / \mathrm{mL}$ final concentration, unless mentioned otherwise. Table 3 shows the residual microbial load with and without tetracycline when Salacia raw material and Salacia extract as used as starting materials respectively.

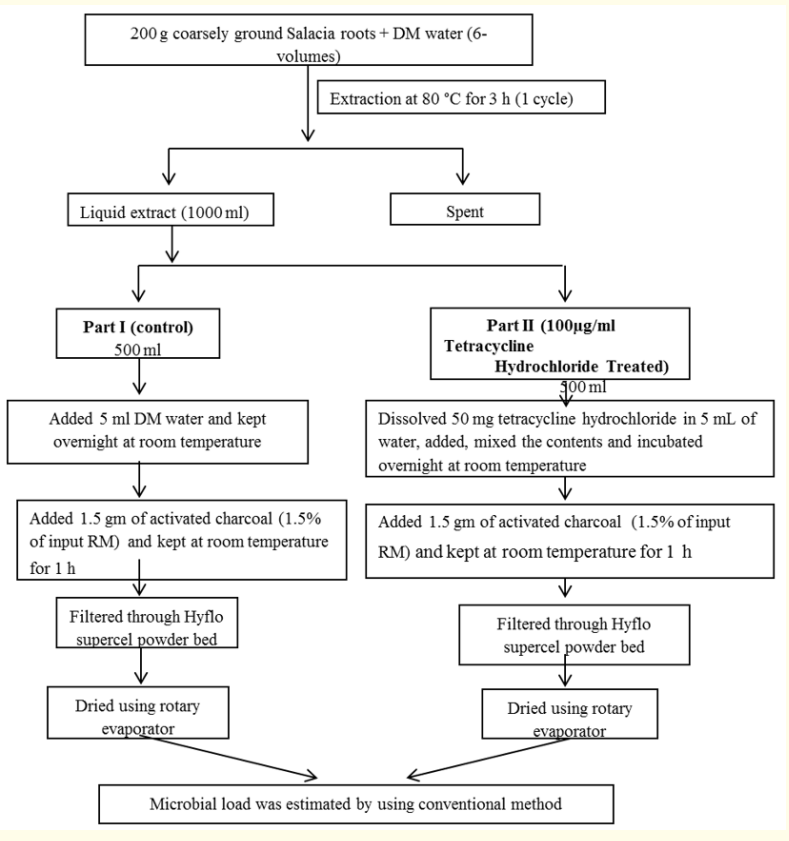

Figure 2A: Flow chart of process of Salacia reticulate raw material with and without tetracycline.

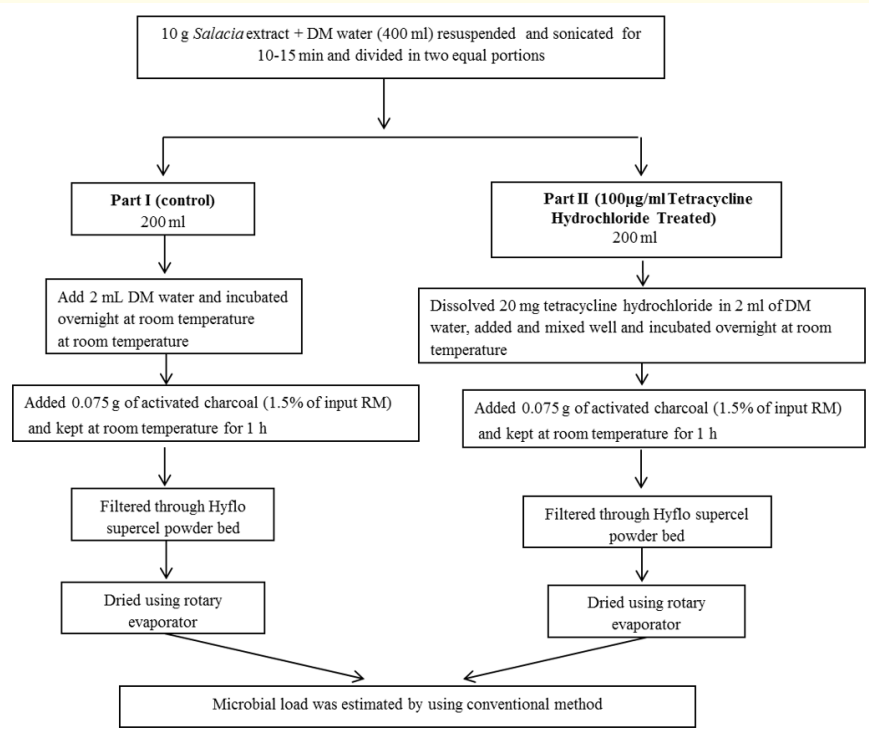

Figure 2B: Flow chart of process of Salacia reticulata extract with and without tetracycline.

\begin{tabular}{|c|c|c|c|c|c|}
\hline Sr. & Sample Name & Dilution & No. of & TVC & \% cfu re- \\
No. & Factor & colonies & $\begin{array}{c}\text { (cfu/ } \\
\text { gm) }\end{array}$ & \\
duction
\end{tabular}

Table 2A: Effect of different concentration of tetracycline on manufacturing process of Salacia on the residual microbial load.

\section{Estimation of residual tetracycline}

The residual tetracycline content in the Salacia extracts when measure by HPLC showed $>95 \%$ reduction in comparison to what was used in the starting of the process. Figures 3,4 and 5 shows the HPLC chromatograms of standard tetracycline and residual tetracycline in Salacia extract made after following flow chart 2 and 3 respectively. 
Characterization of the Microbes Isolated from Salacia reticulata Raw Material and its Extract: A Simple Method to Reduce the Microbial Load in Herbal Products

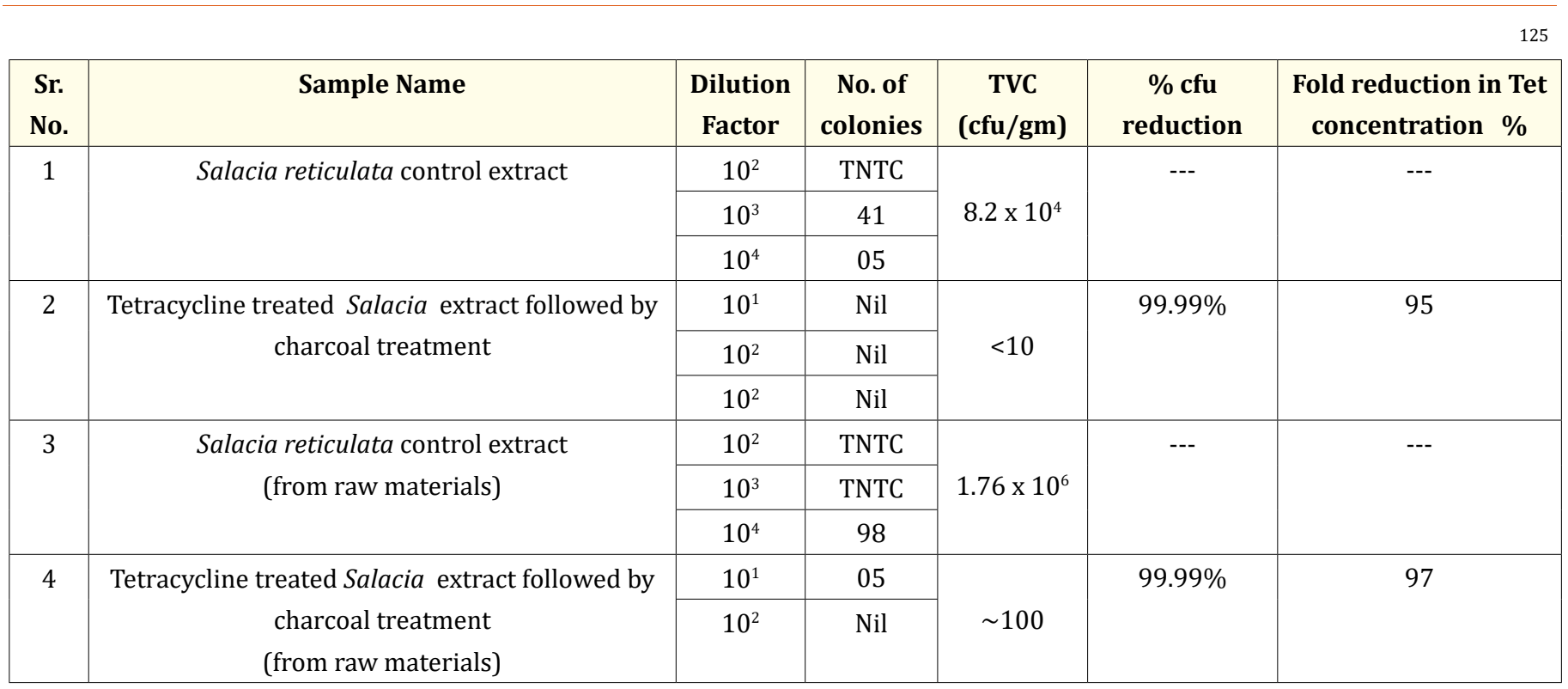

Table 3: Effect of tetracycline treatment on microbial load of Salacia extract.

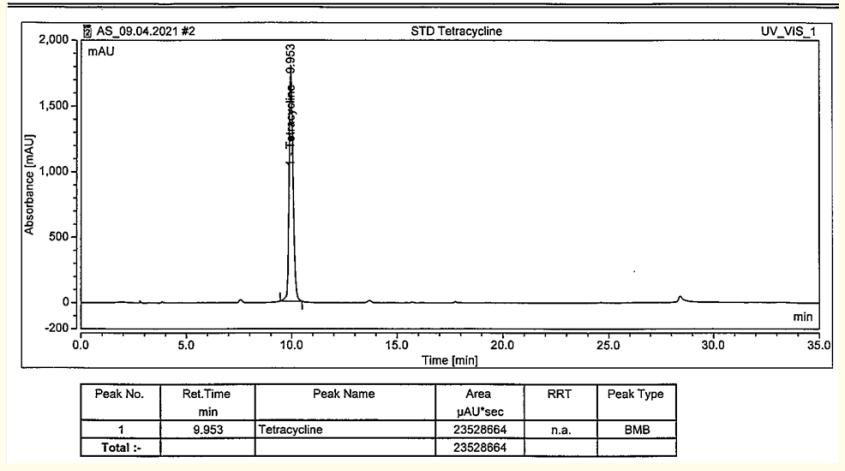

Figure 3: HPLC chromatogram of standard tetracycline (1000 ppm). Note the retention time of 9.953. The $X$ axis denotes the time in ( $\mathrm{min}$ ) while the $\mathrm{Y}$ axis denotes the absorbance ( $\mathrm{mAu}$ ). The wavelength chosen for the HPLC runs was $277 \mathrm{~nm}$.

\section{Discussion}

Our present study reveals Bacillus spp. as the predominant bacteria in the herbal extract of Salacia. Our observations corroborate reports of Shah and Pokhrel [17] who assessed herbal medicines from Nepal and reported Bacillus sp to be a major contaminant. Similarly, Esimone., et al. [18] and Okunlola., et al. [19], reported Bacillus subtilis as the predominant contamination in the herbal extracts they tested and Adeleye., et al. [9], who detected the pres-

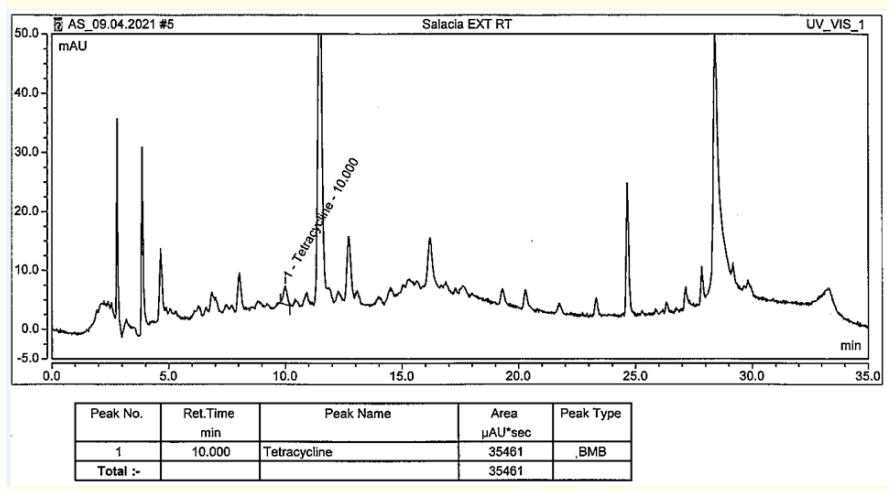

Figure 4: HPLC chromatogram of residual tetracycline after treatment of Salacia raw material as per the process depicted in

Figure 2A.

ence of Bacillus sps. in herbal raw materials of Hippocratea indica, Nauclea latifolia, Enantia sp., Citrus medica var acida, and the bark of Mangifera indica etc. Other species of Bacillus, including B. amyloliquefaciens, B. cereus, B. licheniformis, B. megaterium, B. pumilus and $B$. subtilis, have been also isolated from the inner tissues of healthy plants, and some strains appear to have important roles in growth promotion and plant protection [20]. 


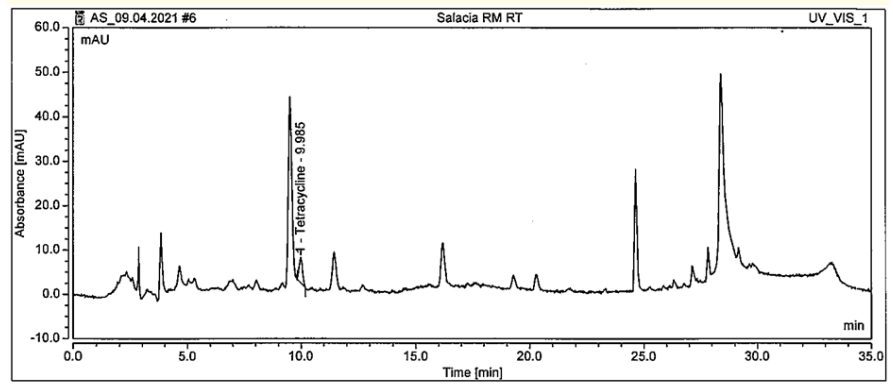

\begin{tabular}{|c|c|l|c|c|c|}
\hline Peak No. & $\begin{array}{c}\text { Ret Time } \\
\text { min }\end{array}$ & Peak Name & $\begin{array}{c}\text { Area } \\
\mu A U^{\prime} s 0 c\end{array}$ & RRT & Peak Type \\
\hline 1 & 9.985 & Tetracycline & 58360 & n.a. & BMB \\
\hline Total :- & & & 58360 & & \\
\hline
\end{tabular}

Figure 5: HPLC chromatogram of residual tetracycline after treatment of Salacia extract as per the process depicted in Figure 2B.

Bacillus is widely distributed in the environment although the primary habitat is the soil. These organisms are usually found in decaying organic matter, dust, vegetable, water, and some species are part of the normal flora. Food-borne B. licheniformis outbreaks are predominantly associated with cooked meats and vegetables and toxin-producing isolates of $B$. licheniformis from industrially produced baby food have been described by Salkinoja-Salonen., et al. [21] and from Vitis ninifera plants [22].

The herbal preparations are made from plants grows on soil, which is the natural habitat of Bacillus sps. Improper drying, inadequate heat processing, improper handling of products and contaminated equipment are other possible sources of Bacillus sp in herb. The spore of Bacillus resists environmental stress and enables the organism to withstand adverse conditions for long term survival.

With the accumulation of $16 \mathrm{~S}$ rRNA gene sequence data, there are now 56 genera of aerobic endospore formers of Bacillus and over 545 species [23]. Bacillus licheniformis is known to cause foodborne illness, with nausea, vomiting, diarrhoea and after consumption of foods where the microbial counts range from $10^{5}$ to $10^{8} \mathrm{cfu} / \mathrm{g}$ [21]. Bacillus subtilis also has been implicated in foodborne illness with vomiting as the commonest symptom with diarrhea when the bacterial loads of the organism were high $\left(10^{5}-10^{9}\right.$ $\mathrm{cfu} / \mathrm{g}$ ). The resistance of endospores of Bacillus to heat, radiation, disinfectants and desiccation and the adhesive characters of particular spores that facilitate their attachment to processing equip- ment and resistance to cleaning procedures [24] result in these organisms frequently being troublesome contaminants in clinical environments, biotechnological processes and food production.

Though, our study reveals the presence of various sps. of $B a-$ cillus in Salacia reticulata roots and their extracts, we realize that two of the sps observed namely Bacillus aryabhattai and Bacillus zanthoxyli are not a major concern since they are non-pathogenic in nature [25,26]. Moreover, phylogenetic analysis based on $16 \mathrm{~S}$ rRNA gene sequences have shown that Bacillus zanthoxyli is closely related to Bacillus aryabhattai [27]. Bacillus zanthoxyli has been found in Chinese red pepper so our observation of presence of such a Bacillus sps in Salacia extract also supports the observation of Li., et al. [27].

Aspergillus and Penicillium sp have been isolated from herbal extracts [28] and hence our observations of presence of Aspergillus in the Salacia raw material supports similar literature findings. Fungi causes deterioration which adversely affects the chemical composition of the raw materials and thereby decreases the medicinal potency of herbal drugs, hence having a check on their counts in herbal medicinal extracts appears to be critical.

The microbiological quality of some herbal solid dosage forms from public markets, in the city of Sari, Iran was examined by Enayatifard., et al. [29]. These products showed $1.1 \times 10^{3} \mathrm{cfu} / \mathrm{g}$ with Salmonella sp. predominating and no evidence for contamination of the samples by Staphylococcus aureus, Pseudomonas aeruginosa, Escherichia coli and Candida albicans. Our Salacia herbal materials also showed total absence of all the above pathogenic bacteria and hence would be safe for human consumption.

In food animals, for easier administration, the antibiotics are administered to groups simultaneously through the drinking water or feed to treat or prevent disease. Tetracycline, oxytetracycline, and chlortetracycline were approved for animals bred for fur, calves, lambs, poultry, and swine with maximum contents of active ingredient of $80 \mathrm{mg} / \mathrm{kg}$ feed.

Tetracycline is a polyketide protein synthesis inhibitor produced by Streptomyces rimosus and shows broad-spectrum of activity on various infectious bacteria. Employed for their low-cost, tetracyclines have found their use in livestock feed as growth promoters for swine and poultry [30,31].

Citation: Sriram Padmanabhan., et al. "Characterization of the Microbes Isolated from Salacia reticulata Raw Material and its Extract: A Simple Method to Reduce the Microbial Load in Herbal Products". Acta Scientific Microbiology 4.12 (2021): 119-129. 
The permissible limit of tetracycline in sea foods including shrimps, prawns, fish and fishery products is $0.1 \mathrm{ppm}(0.1 \mathrm{mg} / \mathrm{kg})$. Although, we do not see such prescribed limits for herbal medicinal products, one could target the limits set for such antibiotics as per Food Safety and Standards Regulations, 2011. Also, activated charcoal is reported to bind to tetracycline [32] and our experiments do support this literature report. Ji., et al. [33] report that weaker adsorption of tetracyclines on activated charcoal in comparison to carbon nanotubes and graphite. It is tempting to speculate that further reduction of tetracycline in the final herbal extracts can be achieved using such adsorption materials.

Tetracycline is bacteriostatic in nature where it prevents the growth of the bacteria by reversibly binding to the ribosomes and by inhibiting bacterial protein synthesis rather than killing the bacteria in vitro. NDM-1-producing bacterial strains have been found to be resistance to multiple antibiotics but are sensitive to combination of doripenem-tetracycline where these antibiotics display inhibition of key enzymes of NDM-1 strain [34]. It is possible that one could reduce the requirement of antibiotics to suboptimal level of MIC, when used in combination with other effective antibiotics. The microbial load in Salacia raw material ranges from $10^{4}$ to $10^{6}$ $\mathrm{cfu} / \mathrm{g}$ based on time of storage and conditions of storage of the raw material. Kumar., et al. [15] have used gamma irradiation and achieved $4 \log$ of reduction in microbial and yeast and mold counts. Our methodology of using a simple and cost-effective antibiotic assumes critical importance.

Extracts of Bambusa arundinacea, Bidens pilosa, Crotton membranaceus, Elaeis guineensis, Hibiscus sabdariffa, Jatropha curcas, Mallotus oppositifolius, Morinda lucida and Spathodia campanulata have been shown to enhance the inhibitory activity of tetracycline [35]. Since no such enhancement of tetracycline is seen in Salacia, it is safe to use this antibiotic to tackle the microbial load is our opinion.

\section{Conclusion}

Our present study of identification of contaminating microbes in Salacia will prove beneficial for researchers and manufacturers who are ensuring minimal levels of microbes in their final herbal extracts to ensure their products to be safe for human consumption. The results of a study by Agyeman-Duah., et al. [36] reveal significantly high amount of microbial contaminants in herbal powders sold in Ghana and Nigeria [37], constituting a health risk. Therefore, it is recommended that plants to be used in herbal preparations should be properly washed and heated as to reduce or eliminate the presence of Bacillus species. The study demonstrated the presence of non-pathogenic Bacillus sps in Salacia raw material and also its extract prepared using water at $80^{\circ} \mathrm{C}$. Although the limits of microbial counts is acceptable as per European Pharmacopoeia, it is always safe if we have manufacturing process to reduce the presence of microbial load to bare minimum which increases the shelf-life of the product and will not affect the efficacy of the herbal medicines. Therefore, good pre-harvest and post-harvest practices together with hygienic manufacturing practices ought to be followed to minimize the level of microbial contamination in plant materials and their extracts.

In conclusion, following such processes that tackles microbes, all the samples of herbal drugs evaluated will meet the standards for microbial limits as specified in official monographs and they will also make the stability of the products better. Such products will also be safe for human consumption and the health status of consumers will be benefitted to a great extent.

\section{Acknowledgments}

The author thanks Mr. Vinod Jadhav, Chairman SAVA Limited and Mr. Avinaash Mandale, MD, SAVA Limited for their constant source of support and encouragement.

\section{Conflicts of Interest}

None declared.

\section{Financial Support}

None.

\section{Bibliography}

1. Beneduzi A., et al. "Plant growth promoting rhizobacteria (PGPR): their potential as antagonists and biocontrol agents". Genetics and Molecular Biology 35 (2012): 1044-1051.

2. Berg G., et al. "Unraveling the plant microbiome: looking back and future perspectives". Frontiers in Microbiology 5 (2014): 148.

3. Akerele 0. "Nature's medicinal bounty: don't throw it away". World Health Forum 14 (1993): 390-395. 
4. Lima de Sousa CM., et al. "Microbial contamination in herbal medicines: a serious health hazard to elderly consumers". BMC Complementary Medicines and Therapies, 20 (2021): 17.

5. Castronovo LM., et al. "Medicinal plants and their bacterial microbiota: A review on antimicrobial compounds production for plant and human health". Pathogens 10 (2021): 106.

6. Kasilo OMJ and Trapsida JM. "Decade of African traditional medicine, 2001-2010". African Health Monito 14 (2011): 2531.

7. Ekor, M. "The growing use of herbal medicines: issues relating to adverse reactions and challenges in monitoring safety". Frontiers in Pharmacology 4 (2013): 177.

8. Idu MD., et al. "Microbial load of some medicinal plants sold in some local markets in Abeokuta, Nigeria". Tropical Journal of Pharmaceutical Research 9.3 (2010): 251-256.

9. Adeleye IA., et al. "Microbial contamination of herbal preparations In Lagos, Nigeria". Journal of Health, Population and $\mathrm{Nu}$ trition 23.3 (2005): 296-297.

10. World Health Organization (WHO). Regulatory situation of herbal medicine: A worldwide review. World Health Organization, Geneva (1988).

11. Sofowora A. "Medicinal plants and traditional medicine in Africa". Chichester. Wiley (1982): 256.

12. Foote JC. "The microbiological evaluation of chamomile: A dissertation in food and nutrition". Texas Tech University, Texas (2002): 9-19.

13. Ali N., et al. "Evaluation of a method to determine the natural occurrence of aflatoxins in commercial traditional herbal medicines from Malaysia and Indonesia". Food Chemistry and Toxicology 43.12 (2005): 1763-1772.

14. Sharafati R., et al. "Biological characterization of Iranian walnut (Juglans regia) leaves". Turkish Journal of Biology 35 (2011): 635-639.

15. Kumar V., et al. "Effect of gamma irradiation on the antioxidant activity of Salacia Reticulata". International Journal of Traditional and Natural Medicines 5.1 (2015): 15-22.
16. Yewale S., et al. "Benefits of Soleris ${ }^{\circledR}$ over the conventional method for enumeration of microbial load in Salacia Herbal Extract”. Polish Journal of Microbiology 69.4 (2020): 453-462.

17. Shah B and Pokhrel N. "Microbial quality and antimicrobial activity of herbal medicine". Nepal Journal of Science and Technology 13.2 (2012): 191-196.

18. Esimone CO., et al. "Microbiological quality of Herbal preparations marketed in Southeast Nigeria". Journal of Natural Remedies 2.1 (2002): 42-48.

19. Okunlola A., et al. "Evaluation of Pharmaceutical and Microbial Qualities of some Herbal Medicinal Products in Southwestern Nigeria". Journal of Pharmaceutical and Biological Anatomy 2.3 (2007): 661-670.

20. Reva ON., et al. "Bacillus endophyticus sp. nov., isolated from the inner tissues of cotton plants (Gossypium sp.)". International Journal of Systematic and Evolutionary Microbiology 52 (2002): 101-107.

21. Salkinoja-Salonen MS., et al. "Toxigenic Strains of Bacillus licheniformis Related to Food Poisoning". Applied and Environmental Microbiology 65.10 (1999): 4637-4645.

22. Nigris GS., et al. "Biocontrol traits of Bacillus licheniformis GL174, a culturable endophyte of Vitis vinifera cv". BMC Microbiology 18 (2018): 133.

23. Logan NA and Halket G. "Developments in the taxonomy of the aerobic, endospore-forming bacteria". In: Aerobic, Endosporeforming Soil Bacteria Edition (2015): 1-29.

24. Ryu JH and Beuchat LR. "Biofilm formation and sporulation by Bacillus cereus on a stainless-steel surface and subsequent resistance of vegetative cells and spores to chlorine, chlorine dioxide, and a peroxyacetic acid-based sanitizer". Journal of Food Protection 68 (2005): 2614-2622.

25. Bhattacharyya C., et al. "Genome-guided insights into the plant growth promotion capabilities of the physiologically versatile Bacillus aryabhattai strain AB211". Frontiers in Microbiology 8 (2017): 411.

26. Li M., et al. "Bacillus zanthoxyli sp. nov., a novel nematicidal bacterium isolated from Chinese red pepper (Zanthoxylum bungeanum Maxim) leaves in China". Antonie Van Leeuwenhoek 110.9 (2017): 1179-1187. 
27. Anyanwu CU. "Fungal contaminants of powdered herbal drugs sold in parts of Enugu State, Southeast, Nigeria". Plant Product Research Journal 14 (2010): 46 -50.

28. Enayatifard R., et al. "Microbial quality of some herbal solid dosage forms". African Journal of Biotechnology 9.11 (2010): 1701-1705.

29. Chopra I and Roberts M. "Tetracycline antibiotics: mode of action, applications, molecular biology, and epidemiology of bacterial resistance". Microbiology and Molecular Biology Reviews 65.2 (2001) 232-260.

30. Granados-Chinchilla F and Rodríguez C. "Tetracyclines in food and feeding stuffs: From regulation to analytical methods, bacterial resistance, and environmental and health implications". Journal of Analytical Methods in Chemistry (2017): 1315497.

31. Choi KJ., et al. "Removal of tetracycline and sulfonamide classes of antibiotic compound by powdered activated carbon". Environmental Technology 29.3 (2018): 333-342.

32. Ji L., et al. "Mechanisms for strong adsorption of tetracycline to carbon nanotubes: A comparative study using activated carbon and graphite as adsorbents". Environmental Science and Technology, 43 (2009): 2322-2327.

33. Maryam L., et al. "Synergistic effect of doripenem in combination with cefoxitin and tetracycline in inhibiting NDM-1 producing bacteria". Future Microbiology 14 (2019): 671-689.

34. Gbedema SY., et al. "Modulation effect of herbal extracts on the antibacterial activity of tetracycline". International Journal of Contemporary Research and Review 1.4 (2010): 1-5.

35. Agyeman-Duah E., et al. "Microbial quality of herbal powders in Ghana”. Edorium Journal of Microbiology 3 (2017): 10-17.

36. Christiana NC and Tope O. "Microbial quality of herbal preparations sold in some parts of Nigeria". GSC Biological and Pharmaceutical Sciences 6.3 (2019): 076-084.

\section{Volume 4 Issue 12 December 2021}

(C) All rights are reserved by Sriram Padmanabhan., et al.

Citation: Sriram Padmanabhan., et al. "Characterization of the Microbes Isolated from Salacia reticulata Raw Material and its Extract: A Simple Method to Reduce the Microbial Load in Herbal Products". Acta Scientific Microbiology 4.12 (2021): 119-129. 